\title{
Oral infusion and taste preference behavior in the white rat $^{1}$
}

\section{W. B. VANCE, Indiana University, Bloomington, Ind. 47401}

Preferences for sucrose, saccharin, and sodium chloride solutions were studied by the two-bottle technique while varying concentrations of the same solutions were continuously infused into the oral cavity. Increasing the infusate concentration of sucrose and saccharin linearly decreased preference, while sodium chloride preference was equally depressed at all concentrations of infusate.

There have been several indications that the composition of oral secretions may be important in altering afferent gustatory activity and, thereby, in producing alterations in taste-preference behavior. Richter \& Eckert (1938) were the first to suggest that the increased sodium appetite of adrenalectomized rats was due to a decreased sodium content of saliva, which, in turn, altered the gustatory receptor output. That there is a reduction in salivary sodium composition in human adrenal pathology and other disease states has been repeatedly demonstrated by Henkin and his colleagues (Henkin et al, 1962; Henkin \& Solomon, 1962; Henkin \& Power, 1962). Similar changes in salivary sodium content have been reported in the parotid secretions of sodium-depleted calves (Bell, 1963). In addition, ligation of the principle salivary ducts leads to marked changes in the preference of white rats for sodium and quinine solutions and results in a complete reversal of the sucrose-rejection behavior of pancreatectomized animals (Vance, 1965). Bartoshuk et al (1964) have further demonstrated the strict dependence of human thresholds for sodium chloride on the adapting concentration of sodium chloride solutions bathing the tongue.

On the other hand, Pfaffmann \& Bare (1950), and more recently Nachman \& Pfaffmann (1963), find no differences in the electrophysiological threshold or overall sensitivity for sodium chloride in adrenalectomized or sodium-deficient rats as judged from the response of the chorda tympani. Also, as Pfaffmann (1963) has observed, given the extremely rapid rate of recovery from prior adaptation in the gustatory system, one would not expect adaptation to be a factor for more than the first few minutes in any preference test.

It is nonetheless possible that an altered salivary composition could lead to some long-term modification of the peripheral response (such as an alteration in patterned response) that is not revealed in the summated chorda tympani potential. It is also possible that long-term adaptation to an altered salivary composition might produce an altered central state that, in turn, could modify responsiveness to taste stimuli.

In the present experiments, the modification of taste preferences by substances infused directly into the oral cavity was assessed in the hope that long-term adaptation effects in the gustatory system might be further clarified.

\section{METHOD}

Three male Sprague-Dawley rats (ca $350 \mathrm{~g}$ ) served as $\mathrm{Ss}$ in each of three preference tests for sodium chloride, sucrose, and sodium saccharin solutions. Each animal was fitted with an intraoral canula by drilling a hole through the nasal bone and hard palate, through which was passed a length of polyethylene tubing (PE 90). The tubing was then passed through a small plastic disk (4 mm diam) and the end of the tubing flared with a flame. The disk was then drawn tightly against the hard palate and the other end of the tubing connected to an overhead swivel joint, which, in turn, was connected to a peristaltic pump.

The animals were housed inidividually, each cage being fitted with two drinking tubes for recording fluid intake. Preference tests were conducted by the two-bottle technique (one containing tap water and the other the test solution), with bottle position being changed every $24 \mathrm{~h}$ to correct for position preference. The taste-preference tests consisted in testing a single concentration of solution while infusing into the oral cavity differing concentrations of the same substance. Specifically, the preference for a $10 \%(\mathrm{w} / \mathrm{v})$ concentration of sucrose was tested while concentrations of $0 \%\left(\mathrm{H}_{2} \mathrm{O}\right), 5 \%, 10 \%$, $15 \%$, and $20 \%$ sucrose were being infused into the oral cavity; for sodium chloride, a preference for a $1.0 \%$ solution while concentrations of $0 \%\left(\mathrm{H}_{2} \mathrm{O}\right), 0.5 \%, 1.0 \%$, $1.5 \%, 2.0 \%$, and $2.5 \%$ sodium chloride were being infused; and for sodium saccharin, a preference for a $0.1 \%$ solution while varying the infusate over concentrations of $0 \%\left(\mathrm{H}_{2} \mathrm{O}\right), .05 \%, .10 \%$, $.15 \%, .20 \%$, and $.25 \%$. In addition, preferences for each of the three substances were determined in the absence of any infusion prior to each test. The infusion rate was $1 \mathrm{ml} / \mathrm{h}$, and each data point was determined over a minimum period of 5 days (usually 7 to 8 days). Food was present ad lib for all tests.

\section{RESULTS}

The results of sucrose infusion on the preference for a $10 \%$ sucrose solution are given in Fig. 1. With no infusion, the animals show the typical high preference for sucrose, and there is no change in preference when water is being infused. With increasing sucrose infusate concentration, the preference declines up to $15 \%$, at which point sucrose intake reaches a level equal to the ad lib water intake. There is no consistent effect of varying infusate concentration on water intake during the preference test, water intake remaining minimal throughout the range of infusate concentrations.

The results of the sodium chloride test are presented in Fig. 2. In contrast to the orderly decline in sucrose preference with increasing concentration of sucrose infusate, there is no relation between concentration and preference for the $1.0 \%$ sodium chloride solution. At zero concentration $\left(\mathrm{H}_{2} \mathrm{O}\right)$, there is a marked reduction in sodium chloride intake, which is maintained over the entire concentration range of infusates. Total fluid intake also remains fairly constant up to the $2.0 \%$ concentration, where there is a marked increase.

The preference test for $0.1 \%$ saccharin solution (Fig. 3) is affected by saccharin infusion in a manner generally similar to the preference for sucrose solution. There is, however, a general drop in water intake at all concentrations of infusate, and an increase in saccharin intake at $0 \%\left(\mathrm{H}_{2} \mathrm{O}\right)$ and $.05 \%$. Thereafter, the preference declines linearly until, at a concentration of $.25 \%$, the saccharin preference is totally abolished. Total fluid intake (saccharin + water) remains constant and equal to the total ad lib water intake ( $32 \mathrm{ml} /$ day), up to

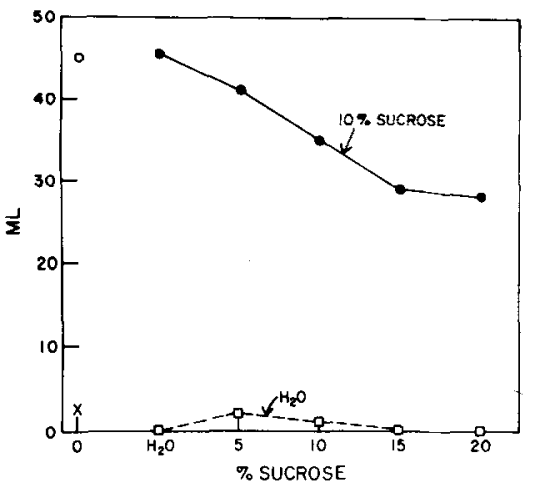

Fig. 1. The effects of infusion of different concentrations of sucrose on the preference for a $10 \%$ sucrose solution. 


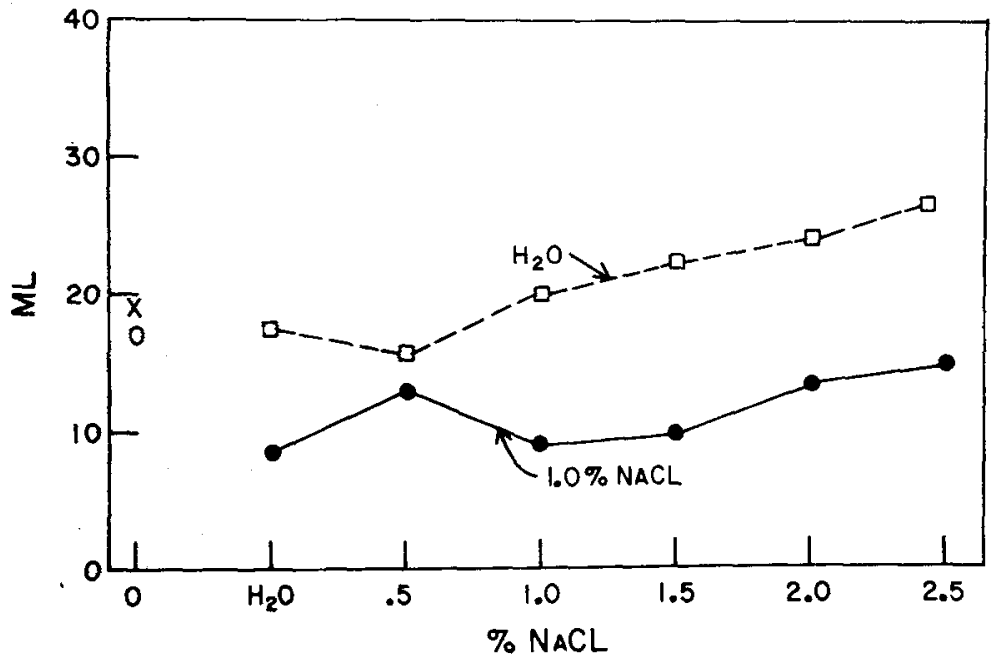

an infusate concentration of $.01 \%$, and then declines to a level of $22.7 \mathrm{ml} /$ day at $.25 \%$.

\section{DISCUSSION}

The results clearly demonstrate an effect of oral infusion on the preferences for sucrose and saccharin. In the case of sucrose, the preference declines with increasing concentration of infusate up to a concentration of $15 \%$, at which point sucrose intake is about equal to the ad lib water intake $(32 \mathrm{ml} / \mathrm{day})$. While this represents a $66 \%$ reduction in sucrose intake from the no-infusion condition, the animals are still displaying a near- $100 \%$ preference for sucrose. For saccharin, on the other hand, there is both a reduction in saccharin intake and an increase in water intake such that, at the highest infusate concentration $(.25 \%)$, there is no evidence of preference.

The sodium chloride preference shows little dependence on concentration of infusate. There is a decrease in preference at $0\left(\mathrm{H}_{2} \mathrm{O}\right)$, which is maintained over the entire range of concentrations. The increase in total fluid intake at the $2.0 \%$ and $2.5 \%$ concentrations is most likely due to the increased osmotic diuresis produced by these higher sodium concentrations, the isorrheic point for the rat being about $1.7 \%$ (Wolff, 1958). It is interesting to note that Mook (1963) found oral factors to be of less importance in sodium chloride preference than in sucrose and glucose preference.

The mechanism of the modification of taste preferences by intraoral infusion is not clear, but there are at least three posibilities: Continuous long-term infusion could alter the peripheral receptor response

Fig. 3. The effects of infusion of different concentrations of saccharin on the preference for a $0.1 \%$ saccharin solution.
Fig. 2. The effects of infusion of different concentrations of sodium chloride on the preference for a $1.0 \%$ sodium chloride solution.

$B E L L, F, R$. The variation in taste thresholds of fuminants associated with sodium depletion. In Y. Zotterman (Ed.), Olfaction and taste. New York: Macmilian, 1963. Pp. 299-307.

HENKIN, R. I., \& POWELL, G. F. Increased sensitivity of taste and smell in cystic fibrosis. Science, 1962, 138, 1107-1108.

HENKIN, R. I., \& SOLOMON, D. H. Salt-taste threshold in adrenal insufficiency in man. Journal of Clinical Endocrinology \& Metabolism, 1962, 22, 856-858.

HENKIN, R. I., GILL, J. R., BARTTER, F. C., \& SOLOMON, D. H. On the presence and character of the Addisonian patient to taste salt. Journal of Clinical Investigation, 1962, 41, 1364-1365.

MOOK, D. G. Oral and postingestional determinants of the intake of various solutions in rats with esophageal fistulas. Journal of Comparative \& Physiological Psychology, $1963,56,645-649$.

NACHMAN, M., \& PFAFFMAN, C. Gustatory nerve discharge in normal and sodium-deficient rats. Joumal of Comparative \& Physiological Psychology, 1963, 56, 1007-1011.

PFAFFMAN, C. Taste stimulation and preference behavior. In Y. Zotterman (Ed.), Olfaction and taste. New York: Macmillan, 1963. Pp. 257-273.

PFAFFMAN, C., \& BARE, J. K. Gustatory nerve discharges in normal and adrenalectomized rats. Journal of Comparative \& Physiological Psychology, 1950, 43, 320-324.

RICHTER, C. P., \& ECKERT, J. F. Mineral metabolism of adrenalectomized rats studied by the appetite method. Endocrinology, 1938, $22,214-224$.

VANCE, W. B. Observations on the role of salivary secretions in the regulation of food and fluid in take in the white rat. Psychological Monographs, 1965, 79, 1-22.

WOLFF, A. V. Thirst. Springfield, I1l: Charles C Thomas, 1958.

\section{NOTE}

PFAFFMAN, L. M., MCBURNE solutions after adaptation to sodium chloride: Implications for the "water taste." Science, $1964,143,967-968$.

1. This study was supported by NSF Grant NB05940-04.

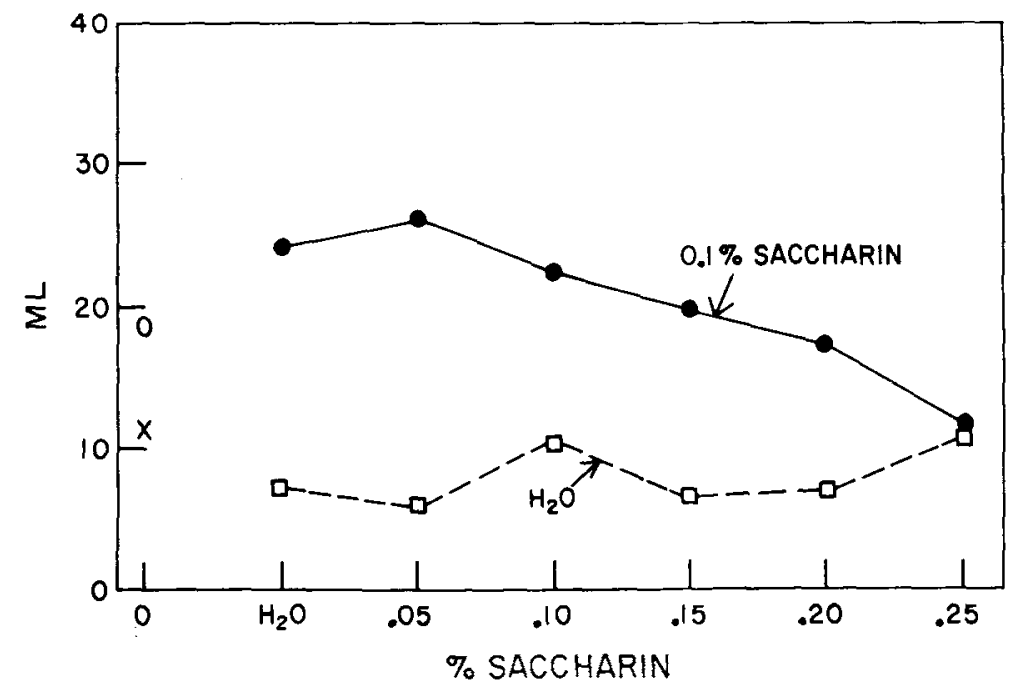

